Pak. j. sci. ind. res. Ser. A: phys. sci. 201356 (2) 93-99

\title{
Thermo-Kinetics Studies of Dye Removal with Kaolin from Tectona grandis and Indigo Dye Effluents
}

\author{
Abayomi Olagundoye Adetuyi*, Abdul-Akeem Alaba Mojibola and Jamiu Mosebolatan Jabar \\ Department of Industrial Chemistry, Federal University of Technology, P.M.B 704, Akure, Ondo State, Nigeria
}

(received May 15, 2012; revised August 28, 2012; accepted September 12, 2012))

\begin{abstract}
The kinetics and thermodynamic behaviour of dye molecules removed from Tectona grandis and indigo dye effluents using kaolin as the coagulant were studied and the results obtained were compared with the commercial alum (as standard). Comparison of data obtained from Langmuir and Freundlich isotherms indicated that the coagulation process was chemisorptions. The isotherm parameters of Langmuir isotherm such as coagulation capacity $\mathrm{Q}_{0}$; coagulation energy intensity $\mathrm{b}$; and correlation coefficient $\mathrm{R}^{2}$, in this study were greater than that of Freundlich. The correlation coefficient of the pseudo-second-order kinetics was almost equal to unity and the values of $\mathrm{q}_{\mathrm{e}(\mathrm{Cal}) \mathrm{s}}$ were of insignificant difference from the corresponding $\mathrm{qe}(\exp$.$) and these made the pseudo-second-order kinetics fitted well with the coagulation$ process. The thermodynamic parameters $(\Delta \mathrm{H}$ and $\Delta \mathrm{S})$ obtained indicated that the coagulation process was endothermic and spontaneous, respectively. The negative values of $\Delta \mathrm{G}$ shows the irreversible nature of the coagulation process and the correlation coefficients $\left(\mathrm{R}^{2}\right)$ closed to unity indicates the fitness of the coagulation thermodynamics with the experimental data.
\end{abstract}

Keywords. coagulant, effluents, kinetics, endothermic, thermodynamics

\section{Introduction}

Waste water generated at various stages in textile industry differ in composition, strength and volume. When not properly treated before discharged into rivers, it pollutes the receiving water body by causing injury to the aquatic plants, animals and making the water unfit for human consumption (Dae-Hee et al., 1999).

According to Chakrabarti et al. (1988) most of the available dyes and pigments consisting of over 7,000 different chemical structures used in textile industry are completely resistant to biodegradation processes and for this reason, physical process for their removal from the effluent is recommended. Chemical process may increase the harmful effect of the effluent on the receiving water body (Pitter and Chudoba, 1990). The conventional physical methods of treating effluent are sorption with the aid of chitin called ozonization method (Safarik, 1995), organic carbon ( Murphy et al., 1992; Gupta et al., 1990), and electrochemical oxidation (Lin and Peng, 1994). The high cost of the above mentioned methods led researchers to look for cost effective method (called coagulation) with equal or more removal efficiency than the conventional treatment methods.

*Author for correspondence; E-mail: yomiadetuyi2002@ yahoo.com
Coagulation method has been found easy to operate and energy saving treatment alternatives (Hassani et al., 2008). It can be expressed as the conversion of colloidal and dispersal particles into small visible floc upon addition of a simple coagulant. It brings about compression of the electrical double layer surrounding each suspended particle, as a result of decrease in the magnitude of the repulsive interactions between particles and destabilization of the particles. The most common coagulants used in wastewater treatment are alum $\mathrm{Al}_{2}\left(\mathrm{SO}_{4}\right)_{3} \cdot 12 \mathrm{H}_{2} \mathrm{O}$, poly aluminium chloride (PAC) and sometimes kaolin. Poly aluminium chloride is more effective than alum in wastewater treatment but highly expensive and more toxic than alum with demerit of skin infection (like eczema) on consumer of the treated wastewater. As a result of these, kaolin is mostly preferred due to its abundance, environmental friendly and availability at low cost (Ma and Wang, 2006; Exall and Vanloon, 2003).

Kaolin has been reported by Ma and Wang (2006) to be used in treatment of oil polluted water with about $99 \%$ removal of chemical oxygen demand, biological oxygen demand, total dissolve solids and hardness. Other areas where it is utilized are pharmaceutical industry, for production of drug used in treatment of various gastrointestinal problems; cosmetics for 
production of talc; production of glossy paper for magazine and newspaper; paints production for gloss level control, and insecticides to control arthropods (Barker et al., 2007; Belloto et al., 1995). The active chemical component responsible for wastewater treatment in kaolin is aluminium silicate hydroxide $\left(\mathrm{Al}_{2} \mathrm{Si}_{2} \mathrm{O}_{5}(\mathrm{OH})_{4}\right)$ popularly called kaolinite. It is a fine, white layered silicate mineral with one tetrahedral sheet linked through oxygen atom to one octahedral sheet of alumina octahedral (Deer et al., 1992).

Thus, this research was primarily designed to focus on the kinetic and thermodynamic studies of the coagulation of T. grandis and indigo dyes' effluents using kaolin as coagulant.

\section{Materials and Methods}

The tender leaves of teak plant (Tectona grandis) and kaolin $\left(\mathrm{Al}_{2} \mathrm{Si}_{2} \mathrm{O}_{5}(\mathrm{OH})_{4}\right)$ were obtained from forestry plantation and Industrial Design Department of Federal University of Technology, Akure, Nigeria, respectively. Alum $\left(\mathrm{Al}_{2}\left(\mathrm{SO}_{4}\right)_{3} \cdot 12 \mathrm{H}_{2} \mathrm{O}\right)$ was purchased from Pasca Chemicals Store, Akure, Nigeria. Indigo dye and prebleached white cotton fabric were purchased from a dyestuff market in Akure, Nigeria. All the chemicals and equipment used were of analytical grade and obtained from Chemistry Department of Federal University of Technology, Akure, Nigeria.

Coagulation process. The effluents used in this study were procured from pilot dyeing of cellulosic fabric with indigo and the extracted $T$. grandis dye. These dye effluents then were subjected to coagulation/ flocculation process via jar experiment.

The effect of coagulant dosage, contact time and temperature on colour removal was studied by coagulation of $T$. grandis and indigo dye effluent with kaolin. The coagulant dosage was varied from 0.2 to $1.0 \mathrm{~g}$ with contact time $1.5 \mathrm{~h}$, temperature of $303 \mathrm{~K}$ and agitation speed of $100 \mathrm{rpm}$ using Gallenkamp orbital shaker. At the end of the contact time, the solutions were centrifuged at $500 \mathrm{rpm}$ for $1.00 \mathrm{~h}$ using uniscope centrifuge machine and the absorbance of the supernatants read at $530 \mathrm{~nm}$ and $410 \mathrm{~nm}$ were used to extrapolate concentrations of the treated $T$. grandis and indigo dye effluent, respectively from prepared working curve using camspec spectrophotometer.

The effect of contact time on dye removal from the effluent was carried out by varying contact time from $0.5-3.5 \mathrm{~h}$ with coagulant dosages of $0.5 \mathrm{~g}$, temperature of $303 \mathrm{~K}$ and agitation speed of $100 \mathrm{rpm}$. At the end of each predetermined contact time, the solutions were treated as done in effect of coagulant dosage to obtain correspond concentration of dye removed from the effluent.

The effect of temperature on dye removal efficiency of the coagulant from generated dyeing effluents was studied by batch technique using Roaches dyeing machine. The coagulation temperature was varied from $303 \mathrm{~K}-343 \mathrm{~K}$ with coagulant dosage of $0.5 \mathrm{~g}$, contact time of $1.5 \mathrm{~h}$ and agitation speed of $100 \mathrm{rpm}$. The dyeing cups were removed from the dyeing machine at the end of $1.5 \mathrm{~h}$ contact time and the solutions therein were treated as done for previous removal technique to obtain percentage dye removal from the treated effluents (Rakhi and Vankar, 2007; Manaskorn et al., 2004).

The data obtained from effect of coagulant dosage, contact time and temperature were used to obtain useful information for the isotherm, kinetics and thermodynamics studies.

Coagulation isotherm. Data obtained from effect of coagulant dosage were used for Langmuir and Freundlich isotherm studies using linearized equations $1 / \mathrm{q}_{\mathrm{e}}=\mathrm{Q}_{\mathrm{o}}$ $+1 / b Q_{0} C_{e}$ and $\log q_{e}=\log K_{f}+1 / n \log C_{e}$, respectively.

Where, $\mathrm{q}_{\mathrm{e}}=$ amount of dye coagulated per unit weight of coagulant $(\mathrm{mg} / \mathrm{g}), \mathrm{C}_{\mathrm{e}}=$ equilibrium concentration of the coagulant $(\mathrm{mg} / \mathrm{L}), \mathrm{Q}_{\mathrm{o}}=$ Langmuir maximum monolayer coagulation capacity (or total number of binding sites) $(\mathrm{mg} / \mathrm{g}), \mathrm{b}=$ coagulation energy $(\mathrm{L} / \mathrm{mg})$, $\mathrm{K}_{\mathrm{f}}$ and $\mathrm{n}$ are Freundlich constants, associated with coagulation capacity and intensity respectively (Himanshu and Vashi, 2010).

Coagulation kinetics. The data obtained from kinetic parameters for the coagulation process were analyzed with Lagergren pseudo-first-order and pseudo-secondorder kinetic models expressed by the equations:

$\log \left(\mathrm{q}_{\mathrm{e}}-\mathrm{q}_{\mathrm{t}}\right)=\log \mathrm{q}_{\mathrm{e}}-\frac{\mathrm{K}_{1} \mathrm{t}}{2.303}$ (Lagergren pseudo-firstorder linearized equation)

$\mathrm{t} / \mathrm{q}_{\mathrm{t}}=1 / \mathrm{K}_{2} \mathrm{q}_{\mathrm{e}}^{2}+\mathrm{t} / \mathrm{q}_{\mathrm{e}}$ (Lagergren pseudo-second-order linearized equation)

Where, $\mathrm{qe}_{\mathrm{e}}$ and $\mathrm{qt}$ refer to the quantity of dye coagulated $(\mathrm{mg} / \mathrm{g})$ at equilibrium and at any time, $\mathrm{t}(\mathrm{h})$, respectively, $\mathrm{K} 1$ is the equilibrium rate constant of pseudo-first-order coagulation kinetic $\left(\mathrm{h}^{-1}\right)$ and $\mathrm{K}_{2}$ is equilibrium rate constant of pseudo-second-order coagulation ( $\mathrm{g} / \mathrm{mg} \mathrm{h}$ ) (Adetuyi and Jabar, 2011). 
Coagulation thermodynamics. Model of coagulation thermodynamic was investigated by using second law of thermodynamic equations expressed as:

$\Delta \mathrm{G}=\Delta \mathrm{H}-\mathrm{T} \Delta \mathrm{S}$

$\Delta \mathrm{G}=-\mathrm{RT}$ In $\mathrm{K}_{\theta}$

Equating the above equations, gave Van't Hoff equation below:

$\log \mathrm{K}_{\theta}=\frac{-\Delta \mathrm{H}^{\theta}}{2.303 \mathrm{RT}}+\frac{\Delta \mathrm{S}^{\theta}}{2.303 \mathrm{R}}$

Where, $\mathrm{K}=$ thermodynamic equilibrium constant $\left(\mathrm{C}_{\text {solid }} / \mathrm{C}_{\text {liquid }}\right), \mathrm{C}_{\text {solid }}=$ solid phase dye concentration at equilibrium $(\mathrm{mg} / \mathrm{L}), \mathrm{C}_{\text {liquid }}=$ liquid phase dye concentration at equilibrium $(\mathrm{mg} / \mathrm{L}), \mathrm{T}=$ temperature in Kelvin, $\mathrm{R}=$ universal gas constant $(8.314 \mathrm{~J} / \mathrm{molK})$, $\Delta \mathrm{H}^{\theta}=$ standard enthalpy change $(\mathrm{KJ} / \mathrm{Mol}), \Delta \mathrm{S}^{\theta}=$ standard entropy change $(\mathrm{KJ} / \mathrm{Molk})$ and $\Delta \mathrm{G}=$ free energy change (KJ/Mol) (Chan-Li et al., 2007; Atkins and de Paula, 2006).

\section{Results and Discussion}

The calibration curves of $T$. grandis and indigo dye were prepared at wavelength of maximum absorption $\left(\lambda_{\max }\right) 530 \mathrm{~nm}$ and $410 \mathrm{~nm}$, corresponding to the absorption of reddish-brown and greenish-yellow (leucodye), respectively (Adetuyi and Jabar, 2011; Adetuyi et al., 2002). They were reproducible and linear over the calibration range used in this study.
Dye removal efficiency. The quantity of dye removed increased from 90.47 to $99.36 \%$ as coagulant dosage increased from $0.2 \mathrm{~g}$ to $1 \mathrm{~g}$ in $T$. grandis while that of effluent from indigo dye was increased from 89.97 to $99.23 \%$ using kaolin as coagulant, as against treatment using alum as standard coagulant with percentage removal of 88.98 to $98.73 \%$ of $T$. grandis dye from the effluent and $88.43 \%$ to $98.72 \%$ indigo dye was removed from the effluent as coagulant dosage increased from $0.2 \mathrm{~g}$ to $1 \mathrm{~g}$ (Table 1). The data in this Table shows that kaolin has higher dye/ colour removal efficiency than the standard (alum). Hence, kaolin could be a good substitute of alum in industrial effluent treatment because it is cheaper and abundant.

Increase in contact time and temperature of coagulation process increased the percentage of colour removal in the effluents (Table 1-2). It was equally noticed that kaolin performed better than the chosen standard and it was more effective in treatment of $T$. grandis effluent than that of indigo.

Coagulation isotherm. Langmuir isotherm. Linearized Langmuir equation $1 / \mathrm{qe}_{\mathrm{e}}=\mathrm{Q}_{\mathrm{o}}+1 / \mathrm{bQ}_{\mathrm{o}} \mathrm{C}_{\mathrm{e}}$ was used to obtain isotherm data by plotting a graph of $1 / \mathrm{q}_{\mathrm{e}}$ against $1 / \mathrm{C}_{\mathrm{e}}$ as shown in Fig. 1, where intercept of the graph equal to Langmuir maximum monolayer coagulation capacity, $Q_{0}$ and Langmuir constant $b$, called energy of coagulation process was gotten from the slope of the

Table 1. Effect of coagulant dosage and temperature on Tectona grandis and indigo dye effluents

\begin{tabular}{|c|c|c|c|c|c|c|c|c|c|c|}
\hline \multirow[t]{3}{*}{ Coagulant } & \multicolumn{5}{|c|}{ Coagulant dosage (g) } & \multicolumn{5}{|c|}{ Temperature $(\mathrm{K})$} \\
\hline & 0.2 & 0.4 & 0.6 & 0.8 & 1.0 & 303 & 313 & 323 & 333 & 343 \\
\hline & \multicolumn{5}{|c|}{ (colour removed \%) } & \multicolumn{5}{|c|}{ (colour removed \%) } \\
\hline KT & 90.47 & 92.16 & 95.98 & 98.73 & 99.36 & 93.43 & 95.13 & 97.25 & 98.73 & 99.15 \\
\hline AT & 88.98 & 91.10 & 95.76 & 98.09 & 98.73 & 92.37 & 93.43 & 95.76 & 98.09 & 98.52 \\
\hline KI & 89.97 & 92.03 & 96.40 & 98.72 & 99.23 & 92.55 & 93.83 & 97.17 & 98.72 & 98.97 \\
\hline AI & 88.43 & 91.52 & 95.89 & 98.20 & 98.72 & 92.03 & 93.57 & 96.14 & 98.20 & 98.46 \\
\hline
\end{tabular}

Table 2. Effect of contact time on Tectona grandis and indigo dye effluents

\begin{tabular}{llllclll}
\hline \hline Coagulant & \multicolumn{5}{c}{ Time (h) } \\
\cline { 2 - 8 } & 0.50 & 1.00 & 1.50 & $\begin{array}{c}2.00 \\
\text { Colour removed (\%) }\end{array}$ & 2.50 & 3.00 & 3.50 \\
\hline KT & 91.53 & 94.28 & 96.40 & 97.67 & 98.73 & 98.94 & 98.94 \\
AT & 90.25 & 93.01 & 95.55 & 97.55 & 97.88 & 98.31 & 98.52 \\
KI & 90.23 & 91.77 & 95.37 & 96.92 & 98.20 & 98.46 & 98.46 \\
AI & 89.20 & 90.23 & 95.37 & 96.92 & 98.20 & 98.46 & 98.46 \\
\hline \hline
\end{tabular}

$\mathrm{KT}=$ Kaolin treated $T$. grandis dye effluent; $\mathrm{AT}=$ Alum treated $T$. grandis dye effluent; $\mathrm{KI}=$ Kaolin treated indigo dye effluent; $\mathrm{AI}=$ Alum treated indigo dye effluent. 
graph and it was used to calculate Langmuir dimensionless separation factor, r. Table 3 shows intercept, slope and Langmuir constants for coagulation of $T$. grandis and indigo dyes, the maximum monolayer coagulation capacity $\mathrm{Q}_{\mathrm{o}}$ of the coagulation for dye from the effluents, dimensionless factor $\mathrm{r}$ and correlation coefficient $\mathrm{R}^{2}$ were found to be in order $\mathrm{AT}>\mathrm{KT}$ and $\mathrm{AI}>\mathrm{KI}$. In contrary, the values of Langmuir constant $\mathrm{b}$ were found to be in order $\mathrm{KT}>\mathrm{AT}$ and $\mathrm{KI}>\mathrm{AI}$, while the values of $\mathrm{r}<1$ show that the coagulation process is favourable.

Freundlich isotherm. Figure 2 shows graph of $\log \mathrm{q}_{\mathrm{e}}$ against $\log \mathrm{C}_{\mathrm{e}}$ from which, the slope and intercept are obtained (Table 3) and used to determine the adsorption capacity and intensity of coagulation process, respectively. Adsorption capacity $\mathrm{K}_{\mathrm{f}}$ was in order KT

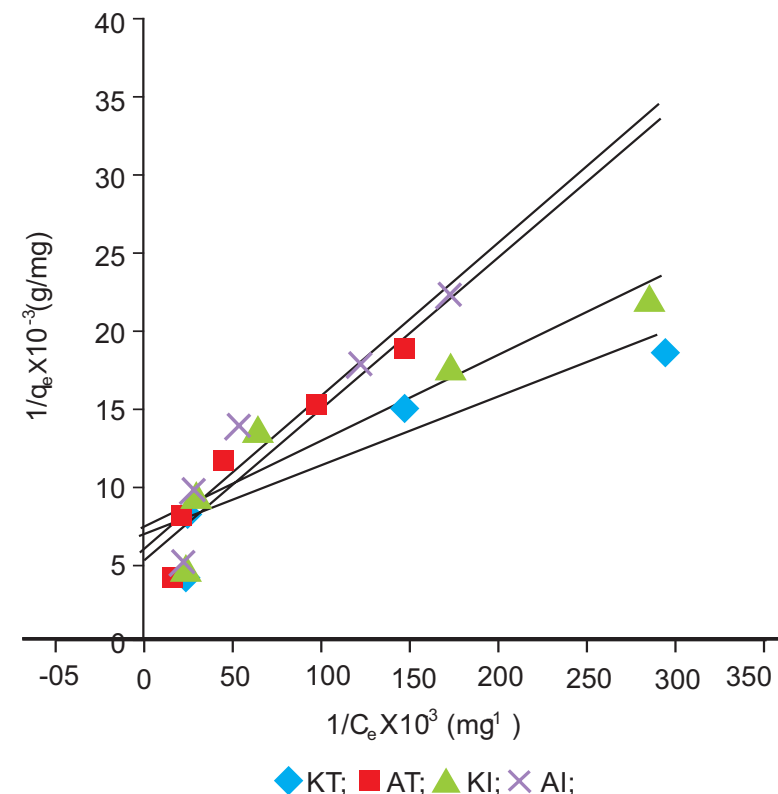

Fig. 1. Linearized Langmuir isotherm of T.grandis and indigo dye.

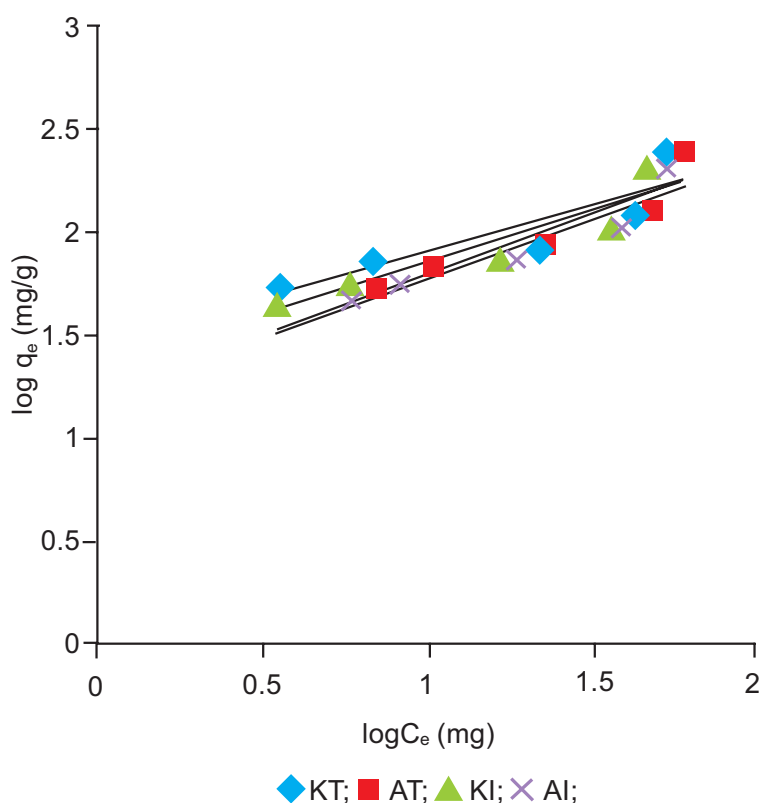

Fig. 2. Linearized Freundlich isotherm for $T$. grandis and indigo dye.

$>\mathrm{KI}$ and $\mathrm{AT}>\mathrm{AI}$ and adsorption intensity was in order $\mathrm{KT}>\mathrm{KI}$ and $\mathrm{AT}=\mathrm{AI}$. Table 3 equally shows that kaolin has greater coagulation capacity and intensity than alum (standard), this observation further support the possibility of kaolin replacing alum for coagulation/ treatment of waste water. The values of coagulation intensity $n>1$ in all treated effluent, is an indication of good coagulation process.

Comparison of data obtained from Langmuir and Freundlich isotherm indicated that the coagulation process was chemisorption since Langmuir coagulation capacities $\mathrm{Q}_{\mathrm{o}}$ was greater than that of Freundlich $\mathrm{K}_{\mathrm{f}}$, Langmuir coagulation energy/ intensity $b$ and correlation coefficient $\mathrm{R}^{2}$ were also greater than that of Freundlich.

Coagulation kinetics. The data obtained from the plot in Fig. 3 (Lagergren first-order-kinetic) did not fit well

Table 3. Coagulation isotherm and thermodynamics parameters for Tectona grandis and indigo dye effluents

\begin{tabular}{|c|c|c|c|c|c|c|c|c|c|c|c|c|c|c|c|c|c|}
\hline \multirow[b]{2}{*}{ Coag. } & \multicolumn{6}{|c|}{ Langmuir } & \multicolumn{5}{|c|}{ Freundlich } & \multicolumn{6}{|c|}{ Thermodynamics (Van't Hoff) } \\
\hline & $\begin{array}{l}\mathrm{C} \times 10^{-3} \\
(\mathrm{mg} / \mathrm{g})\end{array}$ & $\begin{array}{l}\text { Slope } \\
(\mathrm{g})\end{array}$ & $\begin{array}{l}\mathrm{Q}_{\mathrm{o}} \\
(\mathrm{mg} / \mathrm{g})\end{array}$ & $\begin{array}{l}\text { b } \\
(\mathrm{L} / \mathrm{mg})\end{array}$ & $\mathrm{r}$ & $\mathrm{R}^{2}$ & $\begin{array}{l}\mathrm{C} \\
(\mathrm{mg} / \mathrm{g})\end{array}$ & $\begin{array}{l}\text { Slope } \\
\left(\mathrm{g}^{-1}\right)\end{array}$ & $\begin{array}{l}\mathrm{k}_{\mathrm{f}} \\
(\mathrm{mg} / \mathrm{g})\end{array}$ & $\begin{array}{l}\mathrm{n} \\
\left(\mathrm{g}^{-1}\right)\end{array}$ & $\mathrm{R}^{2}$ & $\mathrm{C}$ & $\begin{array}{l}\text { Slope } \\
(\mathrm{K})\end{array}$ & $\begin{array}{l}\Delta \mathrm{H}(\mathrm{KJ} / \\
\mathrm{Mol})\end{array}$ & $\begin{array}{l}\Delta \mathrm{S}(\mathrm{KJ} / \\
\mathrm{MolK})\end{array}$ & $\begin{array}{l}\Delta \mathrm{G}(\mathrm{KJ} / \\
\mathrm{Mol})\end{array}$ & $\mathrm{R}^{2}$ \\
\hline KT & 6.78 & 0.04 & 147.56 & 0.15 & 0.01 & 0.81 & 1.44 & 0.46 & 27.67 & 2.19 & 0.81 & 9.41 & -2.52 & 48.27 & 0.18 & -6.33 & 0.98 \\
\hline AT & 5.18 & 0.10 & 193.13 & 0.05 & 0.03 & 0.90 & 1.21 & 0.59 & 16.18 & 1.71 & 0.87 & 7.97 & -2.11 & 40.40 & 0.15 & -5.8 & 0.94 \\
\hline KI & 7.28 & 0.06 & 137.40 & 0.13 & 0.02 & 0.87 & 1.36 & 0.49 & 22.75 & 2.04 & 0.85 & 9.54 & -2.58 & 49.30 & 0.18 & -5.95 & 0.96 \\
\hline AI & 6.00 & 0.10 & 167.25 & 0.06 & 0.04 & 0.91 & 1.18 & 0.59 & 15.24 & 1.71 & 0.90 & 8.07 & -2.14 & 40.96 & 0.15 & -5.86 & 0.96 \\
\hline
\end{tabular}

Key: Coag. $=$ Coagulation; $\mathrm{C}=$ Intercept. 
Table 4. Coagulation kinetics parameters for Tectona grandis and indigo dye effluents

\begin{tabular}{|c|c|c|c|c|c|c|c|c|c|c|c|}
\hline \multirow[b]{2}{*}{ Coagulants } & \multicolumn{5}{|c|}{ Linearized Lagergren pseudo-first-order } & \multirow[b]{2}{*}{$\begin{array}{l}\mathrm{q}_{\mathrm{e} \operatorname{Exp}} \\
(\mathrm{mg} / \mathrm{g})\end{array}$} & \multicolumn{5}{|c|}{ Linearized Lagergren pseudo-second-order } \\
\hline & $\begin{array}{l}\mathrm{C} \times 10^{-3} \\
(\mathrm{mg} / \mathrm{g})\end{array}$ & $\begin{array}{l}\text { Slope } \\
\text { (mg/gh) }\end{array}$ & $\begin{array}{l}\mathrm{K}_{1} \\
\left(\mathrm{~h}^{-1}\right)\end{array}$ & $\begin{array}{l}\mathrm{q}_{\mathrm{e} \mathrm{Cal}} \\
(\mathrm{mg} / \mathrm{g})\end{array}$ & $\mathrm{R}^{2}$ & & $\begin{array}{l}\mathrm{C} \times 10^{-3} \\
(\mathrm{hg} / \mathrm{mg})\end{array}$ & $\begin{array}{l}\text { Slope } \times 10^{-3} \\
(\mathrm{~g} / \mathrm{mg})\end{array}$ & $\begin{array}{l}\mathrm{K}_{2} \\
(\mathrm{~g} / \mathrm{mgh})\end{array}$ & $\begin{array}{l}\mathrm{q}_{\mathrm{e} \mathrm{Cal}} \\
(\mathrm{mg} / \mathrm{g})\end{array}$ & $\mathrm{R}^{2}$ \\
\hline KT & 1.73 & -0.91 & 2.09 & 54.08 & 0.92 & 107.36 & 0.32 & 9.24 & 0.265 & 108.26 & 1.00 \\
\hline AT & 1.68 & -0.78 & 1.79 & 47.75 & 0.94 & 106.90 & 0.37 & 9.28 & 0.233 & 107.79 & 1.00 \\
\hline $\mathrm{KI}$ & 1.71 & -0.90 & 2.07 & 51.64 & 0.94 & 90.25 & 0.50 & 10.95 & 0.242 & 91.32 & 1.00 \\
\hline AI & 1.74 & -0.90 & 2.06 & 54.95 & 0.94 & 90.01 & 0.56 & 10.96 & 0.213 & 91.24 & 1.00 \\
\hline
\end{tabular}

with the experimental data since the quantity of dye calculated was by far lesser than the quantity of dye coagulated per unit weight of the coagulant obtained in the experiment $\left(\mathrm{q}_{\mathrm{e}(\mathrm{cal})}<<\mathrm{q}_{\mathrm{e}(\exp )}\right)$ but Largergren pseudosecond-order coagulation kinetic (Fig. 4) did. Equally, pseudo-second-order kinetic fitted well in all the coagulation process since the correlation coefficient $\mathrm{R}^{2}$ $\sim 1$ (Table 4), while $\mathrm{R}^{2}<<1$ in pseudo-first-order kinetic (Table 4). The rate constant $\mathrm{K}_{2}$ was highest in $\mathrm{KT}(0.265$ $\mathrm{g} / \mathrm{mgh})$, while that of the AI (0.213 g/ mgh) was the lowest, this showed that the coagulation process was fastest in KT and slowest in AI (Minguan, 2009; Hameed et al., 2007; Rakhi and Vankar, 2007).

Coagulation thermodynamics. The plot of $\log \mathrm{K}_{\mathrm{o}}$ against $1 /$ T gave a straight line graph (Fig. 5) with the intercept and slope used to calculate entropy $\Delta \mathrm{S}$ and enthalpy $\Delta \mathrm{H}$ and subsequently the free energy $\Delta \mathrm{G}$ of the coagulation thermodynamic (Table 3 ). The value

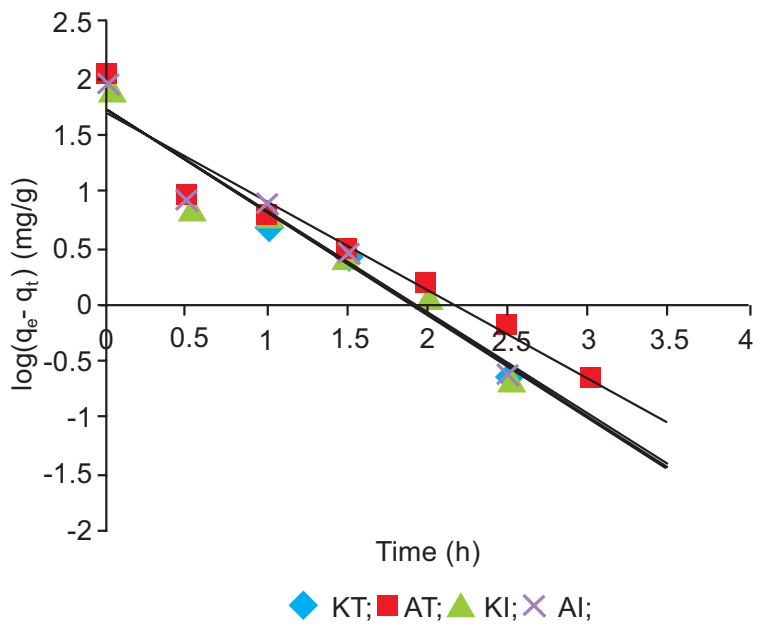

Fig. 3. Linearized Lagergren pseudo-first-order kinetics for the coagulation of $T$. grandis and indigo dye by kaolin and alum.

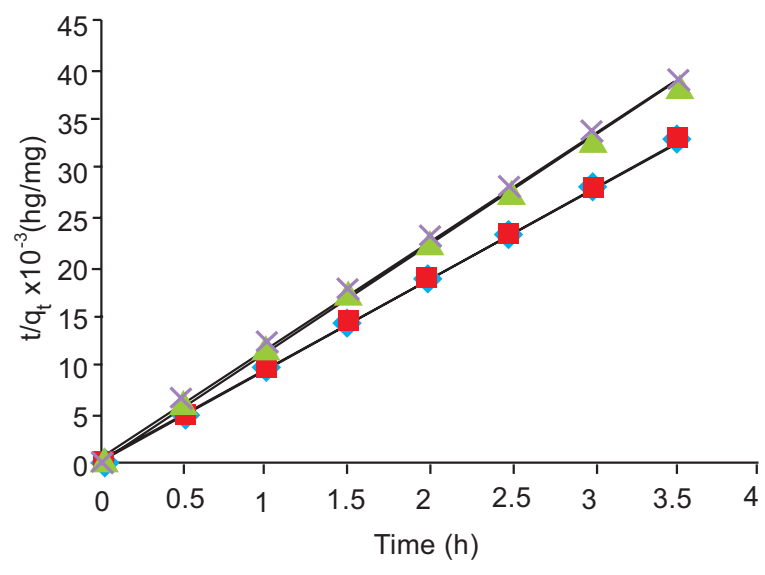

$\mathrm{KT} ; \mathrm{AT} ; \triangle \mathrm{KI} ; \times \mathrm{Al}$;

Fig. 4. Linearized Lagergren pseudo-second-order kinetics for the coagulation of $T$. grandis and indigo dye effluents by kaolin and alum.

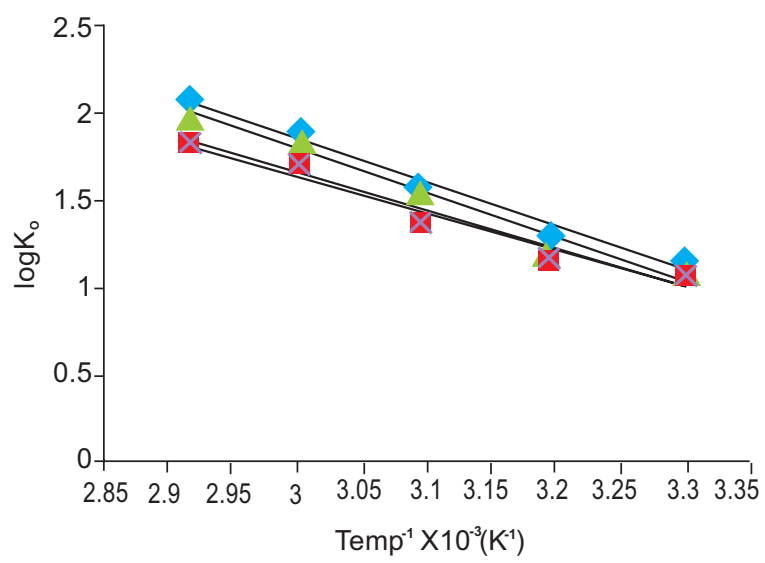

$\mathrm{KT} ; \square \mathrm{AT} ; \triangle \mathrm{Kl} ; \times \mathrm{Al}$;

Fig. 5. Van't Hoff plot for the coagulation of $T$. grandis and indigo dye by kaolin and alum. 
of $\Delta \mathrm{H}$ greater than $40 \mathrm{KJ} / \mathrm{mol}$ in all the coagulation process indicated that the process is endothermic and chemisorption, while the positive and negative values of $\Delta \mathrm{S}$ and $\Delta \mathrm{G}$ are the indication of spontaneity and irreversibility of the process. The correlation coefficients $\left(\mathrm{R}^{2}\right)$ were almost equal to unity in all the coagulation processes, evidence that the thermodynamic process fitted quite well with the experimental data.

\section{Conclusion}

The study showed that kaolin in place of alum can be used effectively in the removal of both $T$. grandis and indigo dyes from their respective dyeing effluents. The thermo - kinetics parameters for the coagulation process favoured chemisorption and obeyed the Lagergren pseudo-second-order model. Also, the positive values of $\Delta \mathrm{H}$ and $\Delta \mathrm{S}$ as well as the negative values of $\Delta \mathrm{G}$ obtained showed that the interactions of the coagulants with the dye effluents were endothermic, spontaneous and favourable.

\section{References}

Adetuyi, A.O., Jabar, J.M. 2011. Kinetic and thermodynamic studies of indigo adsorption of some activated bio-solids. Journal of Chemical Society of Pakistan, 33: 158 - 165.

Adetuyi, A.O., Popoola A.V., Lajide, L. 2002. Isolation and colouring potentials of leave extract of teak plant (Tectona grandis). Journal of Chemical Society of Nigeria, 28: 34-39.

Atkins, P.W., de Paula, J. 2006. Thermodynamics and kinetics. In: Physical Chemistry, vol. 1, 212 pp., $8^{\text {th }}$ edition, W.H., Freeman and Company, USA.

Barker, J.E., Holaschke, M., Fulton, A., Evans, K.A., Powell, G. 2007. Effects of kaolin particle film on Myzus persicae (Hemiptera: Aphididae) behaviour and performance. Bulletin of Entomological Research, 97: 455-460.

Bellotto, M., Gualtieri, A., Artioli, G., Clark, S.M. 1995. Kinetic study of the Kaolinite-Mullite reaction sequence. Part I: Kaolinite dehydroxylation. Physics and Chemistry of Minerals, 22: 207-217.

Chakrabarti, T., Subrahmanyan, P.V.R., Sundaresan, B.B. 1988. Biodegradation of recalcitrant industrial wastes. In: Biotreatment Systems, vol. 2, pp. 171234. CRC Press, Inc., Boca Raton, Florida, USA. Chan-Li, H., Yuwen, L.Y., Chil-Chang, H., Yao-Hui,
H., Chuch-Yung, C. 2007. Adsorption kinetics, thermodynamics and desorption studies of C.I. reactive black 5 on a novel photo assisted Fento catalyst. Dyes and Pigments, 75: 130-135.

Dae-Hee, A., Won-Seok, C., Tai-Il, Y. 1999. Dyestuff wastewater treatment using chemical oxidation, physical adsorption and fixed bed biofilm process. Process Biochemistry, 34: 429-439.

Deer, W.A., Howie, R.A., Zussman, J. 1992. An Introduction to the Rock-Forming Minerals, 2nd edition, 696 pp., Harlow, Longman Scientific and Technical, London, UK and New York, USA.

Exall, N.K., Vanloon, W.G. 2003. Effects of raw water conditions on solution-state aluminum speciation during coagulant dilution. Water Research, 37: 3341-3380.

Gupta, G.S., Prasad, G., Singh, V.N. 1990. Removal of chrome dye from aqueous solutions by mixed adsorbents: fly ash and coal. Water Research, 24: 45-50.

Hameed, B.H., Almad, A.L., Latiff, K.N.A. 2007. Adsorption of basic dye (methylene blue) onto activated carbon prepared from rattan sawdust. Dyes and Pigments, 75: 143- 149.

Hassani, A.H., Seif, S., Javid, A.H., Borghei, M. 2008. Comparison of adsorption process by GAC with novel formulation of coagulation-flocculation for colour removal of textile wastewater. International Journal of Environmental Research, 2: 239-248.

Himanshu, P., Vashi, R.T. 2010. Treatment of textile wastewater by adsorption and coagulation. E-Journal of Chemistry, 7: 1468-1476.

Lin, S. H., Peng, C.F. 1994. Treatment of textile wastewater by electrochemical method. Water Research, 28: 277 - 282.

Manaskorn, R., Sirawan, R., Summate, T. 2004. Removal of reactive dyes from aqueous solution using bagasse fly ash. Songklanakarin Journal of Science Technology, 26: 13-24.

Ma, H.Z., Wang, B. 2006. Multifunctional microsized modified kaolin and its application in wastewater treatment. Journal of Hazardous Materials, 136: 365-370.

Minguan, R. 2009. Natural organic matter removal by coagulation: Effect of kinetics and hydraulic power, pp. 135-136, I WA Publishing, Beijin China 
Murphy, O.J., Hitchens, G.D., Kaba, L., Verostko, C. 1992. Direct electrochemical oxidation of organic for wastewater treatment. Water Research, 26: 443445.

Pitter, P., Chudoba, J. 1990. Biodegrability of Organic Substances in the Aquatic Environment, pp. 7-83, CRS-Press, Boca Raton, Florida, USA.
Rakhi, S., Vankar, P.S. 2007. Dyeing cotton, wool and silk with Hibiscus mutabilis (Gulzuba). Dyes and Pigments, 74: 464-469.

Safarik, I. 1995. Removal of organic polycyclic compounds from water solutions with a magnetic chitosan based sorbent bearing copper phthalocyanine dye. Water Research, 29: 101-105. 